Research Article

\title{
NUMERICAL ANALYSES OF A STRAIGHT BLADED VERTICAL AXIS DARRIEUS WIND TURBINE: VERIFICATION OF DMS ALGORITHM AND QBLADE CODE
}

\author{
Abdullah MURATOĞLU ${ }^{1^{*}}$, M. Sungur DEMİR
}

Wind energy is among the most cost-effective renewable energies. Till date, turbines with different configurations had been designed to harness wind power, each having unique superiorities. Darrieus turbines are one of the mostly investigated vertical axis wind turbines using either experimental or numerical methods. Experimental analyses are time consuming works which requires high amount of effort and expenses. Thus, computational fluid dynamics (CFD) methods have been commonly used by scientists and engineers in order of obtaining detailed performance and illustration of the fluid flow. Contrary to the horizontal axis machines, Darrieus turbines are difficult to be analyzed by CFD algorithms due to high pressure and velocity variations which arise from extreme changes in the angle of attack beyond the stall condition at different azimuthal position of the blades. Therefore, more simplified numerical models are generated employing double multiple streamtube (DMS) theory together with additional improvements. QBlade is one of the mostly used numerical methods based on the lifting line free vortex wake method developed for calculating rotor aerodynamics. The main scope of this study is to design a straight bladed Darrieus turbine ( $D=1028$ $\mathrm{mm}, \mathrm{H}=1460 \mathrm{~mm}, \mathrm{~N}=3$ ) and to verify the double multiple streamtube theory and QBlade algorithm with the experimental and computational works. Analysis results represented good agreement with the previous studies especially at lower TSR ranges. Compare to the experimental results, an overestimation in the power coefficient is obtained at low free stream speed and high TSR ranges after exceeding the peak point. Sensitivity of the model to the Re number variations have also been outlined.

Key words: VAWT, Darrieus, experiment, CFD, validation, numerical, QBlade

\section{Introduction}

After the industrial revolution, global energy consumption has been exponentially increased. The reason behind this increment is mainly per capita energy use and population growth. Today, more than $79-80 \%$ of total global energy use is covered from fossil resources [1]. Extreme oil, coal and gas use resulted high carbon dioxide and other greenhouse gas releases. Annual carbon dioxide emission is

\footnotetext{
1 Department of Civil Engineering, University of Batman, Batman, Turkey (abdullah.muratoglu@batman.edu.tr) https://orcid.org/0000-0001-8981-5983 (Corresponding author)

2 Department of Civil Engineering, University of Batman, Batman, Turkey (muhamed.sungur@batman.edu.tr) https://orcid.org/0000-0003-3631-6325
} 
still rising to be above 39.5 Gtons [1]. Global climate change and global warming are the main detrimental consequences of increasing greenhouse gas intensity in the atmosphere. Huge amount of research is provided by scientists and governmental units to solve the climate change problem. Accordingly, majority of the studies reported that the solution is mainly based on decreasing fossil fuel burning, diversification of energy supply [2] and finding more alternative and renewable solutions for energy production. High availability, low cost, sustainability and cleanness of renewable energy resources [3] such as wind, hydro, biomass and solar energy increased attention of researchers to make more R\&D and technical feasibility studies.

Wind is defined as moving air that is produced as a result of uneven temperature distribution which is originated from solar radiation and earth's rotation [4]. It is characterized as renewable, interminable environmental friendly source of energy, delivering high power outputs [4]. Today, wind energy is considered as the most cost effective solution among other renewables leading its installed capacity being increased day by day [5]. According to the projections, the global installed capacity of wind energy is estimated to exceed $800 \mathrm{GW}$, in the next couple of years [5].

Wind energy is mainly classified into two groups according to the orientation of the central shaft. These are vertical axis (VAWT) and horizontal axis wind turbines (HAWT). Horizontal axis turbines are generally preferred for larger-scale applications and commercial installations [6]. On the other hand, vertical axis turbines are employed either for domestic use or at the places where classical HAWTs are not suitable for application, in terms of efficiency or high cost. Basically, literature studies unveil larger power coefficient scores of HAWTs relative to VAWT machines. However, VAWT have several unique advantages over horizontal axis machines. These systems have a number of blades rotating around a central shaft which is perpendicular to the free stream. Therefore, vertical axis devices can produce energy at various and diffuse velocity conditions [7]. Thus they are independent from the flow direction and yaw angle [8]. On the other hand, cyclic variations in the pressure and velocity, high fatigue loads, vibration and noise problems are among the main disadvantages of vertical axis wind turbine configurations [9]. Also, VAWTs have relatively higher cut-out wind speed values which makes them to be practical in majority of the turbulent and harsh flow environments [10]. Again, so called Betz limit can be exceeded in vertical axis machines [11].

VAWT technology can be categorized in two classes, namely drag and lift type of devices. The most popular drag type turbine is known as Savanious turbines having a number of (semicircular) buckets which is activated by the impact of drag force that is driven by the flow [12]. Similarly, Darrieus turbine have been invented by G. J. M. Darrieus to be used for residential purposes at remote zones in order to overcome blade size and rotational speed limits [13]. Unlike the Savanious turbines, Darrieus rotors are mainly activated by the combination of aerodynamic lift and drag forces generated on 2D blade sections (airfoils). Basically, Savanious turbines have relatively lower cut in speed than Darrieus turbines [12]. On the other hand, Darrieus turbines deliver higher efficiency ranges than Savanious turbines. However, the efficiency still remains below the horizontal axis machines [14]. Detailed representation of power coefficient of various horizontal and vertical axis free flow turbines with respect to their tip speed ratio is illustrated in Fig. 1.

There have been various studies on the aerodynamic performance of Darrieus wind or hydrokinetic turbines. The performance of straight bladed Darrieus turbines have been analyzed by Castelli et al. [16] by comparing the computational fluid dynamics (CFD) results with traditional blade element momentum (BEM) theory. Similarly, another study of Castelli et al. [17] provided a model for determining optimal spatial grid node distribution of Darrieus turbines for CFD analyse s. 
They also validated the numerical simulation results with the experimental data from wind tunnel. Ferreira et al. [18] emphasized the complexity of modelling vertical axis turbines by computational ways due to high velocity and pressure variations at different azimuthal positions of the blade. D'Alessandro et al. [19] developed a mathematical model which analyzes the interaction between flow area and turbine blades in order to analyze the complex flow field around Savanious wind turbines. Scungio et al. [13] investigated wind tunnel performance of a straight bladed micro-scale Darrieus wind turbine at low wind speeds which made of auxiliary airfoiled blades. Rainbird et al. [14] investigated the effect of flow curvature on the performance of Darrieus turbines and they suggested a virtual chamber correction for low order simulation models. Khadir and Mrad [20] numerically investigated the aerodynamic performance of Darrieus wind turbines considering the magnus effect. Ghazalla et al. [21] analyzed Darrieus turbines inside flanged diffuser in order to improve the aerodynamic performance considering different blade sections. Wakui et al. [22] studied on the hybrid configuration of Darrieus and Savanious turbines for standalone wind turbine generator system. Consul et al. [23] investigated the effect of solidity on the performance of vertical axis turbines using numerical approach. Brusca et al. [24] studied the effect of aspect ratio on the performance of straight bladed Darrieus turbines reporting that higher aspect ratios reduces the overall performance.

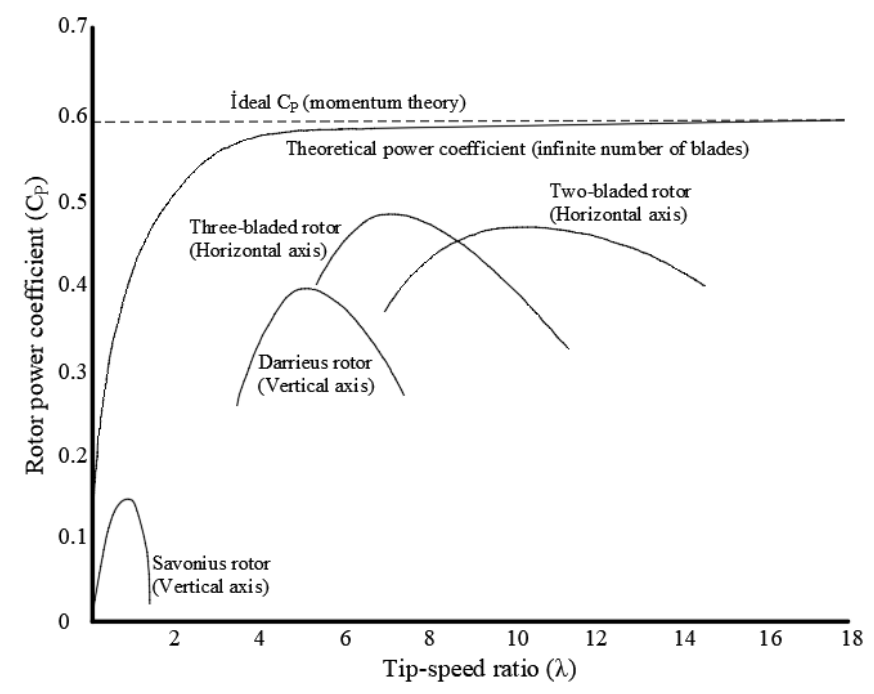

Figure 1. Comparison of vertical and horizontal axis wind turbines in terms of efficiency (Figure is based on [15])

Abovementioned studies reveal that the flow around the Darrieus turbines is quite unsteady necessitating high efforts for CFD modeling. Therefore, employment of more simple numerical models for performance prediction would eliminate the computational effort and expenses of CFD algorithms. QBlade software [25] is a numerical code that have been developed for the design and simulation of horizontal and vertical axis wind and hydrokinetic turbines based on the BEM and double multiple streamtube (DMS) algorithms [26]. The code is developed by Hermann Föttinger Institute of TU Berlin and distributed under General Public License. [27] The model is based on the lifting line free vortex wake (LLFVW) method for calculating the rotor aerodynamics [28]. QBlade runs integrated with the XFOIL code within the graphical user interface and is capable of evaluating airfoil polars and extrapolating the polars for various angles of attack [26]. In the literature, many studies utilized QBlade code for performance analysis or validation of the existing models. Mahmuddin [29] developed a computational method which is based on BEM theory for performance prediction of horizontal axis wind turbines considering tip and root losses by validating the developed 
model with QBlade software. Bianchini et al. [28] implemented the virtual camber transformation into the QBlade algorithm. Suresh and Rajakumar [30] reported the aerodynamic analyses for a $2 \mathrm{~kW}$ small scale HAWT using QBlade algorithm considering different airfoil sections. The effect of Re number on a two bladed HAWT employing QBlade software has been analyzed by Rahimian et al. [31]. Good agreement between BEM and CFD model has been reported. The algorithm has also been used by Akour et al. [32] for determining the power coefficient of a micro wind turbine working under low average wind speed. The code has also been used for verification of 5 MW NREL wind turbine by Barooni et al. [27]. Sensitivity analysis of a Darrieus turbine using Gurney Flaps for power augmentation has been provided using QBlade software for TSR and power curve prediction as a LLFVW model. Smooth and more realistic application of DMS model at uniform interference factors have been attained using QBlade algorithm by Bangga et al. [33]. Consequently, LLFVW model which is applied by QBlade software have been noted to solve accuracy and convergence problems encountered in VAWTs [34].

The main scope of the present study is to model a three bladed H-shaped (straight) Darrieus turbine via QBlade software and to compare the model outputs with the experimental and computational fluid dynamics results of literature studies [16,17,35,36] employing the similar geometry. For this purpose, the turbine geometry that is generated from NACA $002186.5 \mathrm{~mm}$ chord length airfoils having radius of $515 \mathrm{~mm}$ and height of $1460 \mathrm{~mm}$ has been analyzed by QBlade at different free stream speed and tips speed ratio intervals. The modeled geometry and dynamic properties of flow domain are selected to be similar to the abovementioned studies for providing a better comparison and verification.

\section{Theory and method}

\subsection{QBlade and XFOIL algorithms}

QBlade is an open source code that is developed for design and simulation of vertical and horizontal axis wind and hydrokinetic turbines. The model utilizes DMS algorithm for VAWT analyses. The employed blade sections' lift and drag characteristics are evaluated by the XFOIL software which is integrated with QBlade [26]. XFOIL is also an open source interactive algorithm developed for design and analysis of 2D airfoils employing the speed and accuracy of high order panel methods with fully coupled viscous and inviscid interaction method [37]. The performance parameters such as lift, drag, pressure coefficient, etc. of 2D blade sections are evaluated by the XFOIL algorithm. It is a general accepted code that is widely used by the scientific community for aerodynamic analyses [38-40]. In majority of the cases, it becomes impossible to deliver the performance coefficients at high angles of attack beyond the stall conditions using XFOIL, due to the convergence problems. Thus missing data are completed by QBlade software making extrapolations [26] to find out the airfoil performance within $0^{\circ}-360^{\circ}$ angles of attack in which the airfoils stand at different azimuthal positions.

\subsection{Aerodynamics forces on Darrieus turbines}

A typical vertical cross section of the straight bladed Darrieus turbines is shown in Fig. 2. The relative velocity $(w)$ is one of the most important parameters that affects the performance of the complete rotor which is the resultant of both free stream velocity $\left(U_{\infty}\right)$ and blades' tangential velocity $\left(U_{t}\right)$. It varies as a function of the azimuth angle $(\theta)$, which is defined as the angle between the blade 
and the horizontal axis. Relative velocity acted at an angle of attack $(\alpha)$ at different azimuthal position of each blade section generates aerodynamic lift and drag forces which are represented by $C_{L}$ and $C_{D}$. Drag force is parallel to the relative velocity vector, while the lift force is at the perpendicular direction. Then, the normal and tangential components of both lift and drag forces can be written as;

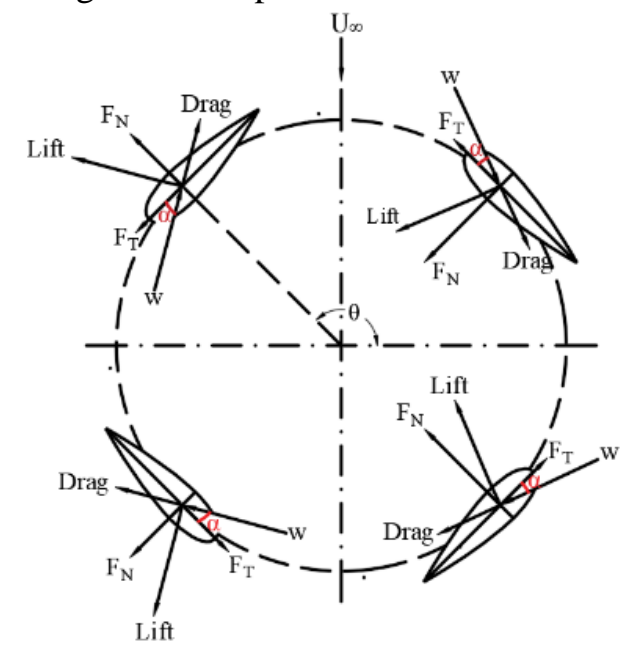

Figure 2. Representation of forces and velocity vectors generated on a typical vertical Darrieus rotor section

$$
\begin{aligned}
& F_{N}=\frac{1}{2} \rho w^{2} h c\left(C_{n}\right) \\
& F_{T}=\frac{1}{2} \rho w^{2} h c\left(C_{t}\right)
\end{aligned}
$$

where, $F_{N}$ is the normal force to the airfoil chord, $F_{T}$ is the tangential force, $\rho$ is the density, $w$ is the relative velocity, $h$ is the blades' height, $c$ is the chord length, $C_{n}$ is the normal force coefficient, and $C_{t}$ is the tangential force coefficient. Consequently, normal and tangential force coefficients can be written as follows;

$$
\begin{aligned}
& C_{n}=C_{L} \cos (\alpha)+C_{D} \sin (\alpha) \\
& C_{t}=C_{L} \sin (\alpha)-C_{D} \cos (\alpha)
\end{aligned}
$$

\subsection{DMS theory}

In order of being a new and emerging technology, the very first attempts of wind turbine methodology is mainly based on classical propeller theories. Blade element momentum (BEM) method which is originally developed to assess the performance of classical airplane propellers by Glauert [41] has been widely used in the scientific community at the first turbine designs works. Then, single streamtube model has been developed by Templin [42] and it has been extended to be parallel dependent streamtubes by Strickland [43] which is called multiple streamtube theory [44]. Aerodynamic streamtube models are generated considering the conservation of momentum equations and the forces on the turbine blades which are equated to vary in streamwise direction [45]. Contrary to the single streamtube model, DMS theory assumes that the entire rotor is produced from a number of adjacent streamtubes [45]. Double Multiple Streamtube theory is developed as a combination of multiple streamtube method and double actuator disk theories [46]. The method is firstly introduced by Paraschivoiu [47,48]. Multiple streamtube method analyzes the flow considering momentum balance of each streamtube which allows velocity variations at perpendicular directions to the free stream [46]. 
However, as a disadvantage, multiple streamtube theory is unable to separately analyze upstream and downstream regions. Thus, double actuator disk theory has been proposed which assumes that two actuator disks has been placed sequentially which are connected at the center of turbine [46]. Then, both theories have been combined as double multiple streamtube (DMS) theory. Consequently, the velocity variations can be taken into account between upstream and downstream part of turbine (Fig. 3). The detailed representation of the DMS theory can be provided based on Biadgo at al. [46] as follows;

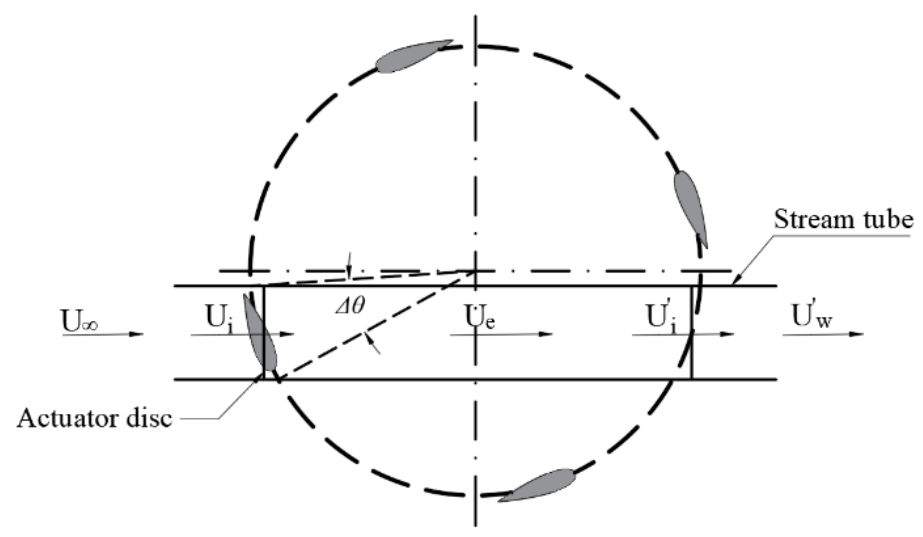

Figure 3. Understanding the DMS theory at a vertical cross section of rotor

DMS assumes that, the streamflow enters to the frontal blades with velocity $U_{i}$ and the velocity is induced to the $U_{i}{ }^{\prime}$ at the rear blades. Similarly, $U_{\infty}$ is the free steam speed, $U_{e}$ is the flow velocity at the center of the turbine and finally $U_{w}{ }^{\prime}$ is the stream speed after the rotor. The induced velocities can be written as;

$$
\begin{gathered}
U_{i}=\frac{U_{\infty}+U_{e}}{2} \\
U_{i}{ }^{\prime}=\frac{U_{e}+U_{w}{ }^{\prime}}{2}
\end{gathered}
$$

The relative velocity vector $(w)$ which is primary responsible velocity vector from the turbine's performance becomes a function of turbine's angular velocity and the induced speed. Thus, two different relative velocity functions can be written for the upstream and downstream halves of the rotor, respectively as follows;

$$
\begin{gathered}
w=\sqrt{\left(\left(u_{i} \sin (\theta)\right)^{2}+\left(u_{i} \cos (\theta)\right)+\omega R^{2}\right)^{2}} \\
w^{\prime}=\sqrt{\left(\left(u_{i}{ }^{\prime} \sin (\theta)\right)^{2}+\left(u_{i}{ }^{\prime} \cos (\theta)\right)+\omega R^{2}\right)^{2}}
\end{gathered}
$$

Finally, the thrust, torque and power coefficients which are solved for $w$ and $w^{\prime}$, separately, can be represented as follows;

$$
C_{T}=\frac{2}{\pi}\left(\frac{B c}{2 R}\right)\left(\frac{w}{U_{\infty}}\right)^{2}\left(C_{t} \frac{\cos \theta}{\sin \theta}-C_{n}\right)
$$




$$
\begin{gathered}
C_{Q}=\left(\frac{B c}{D}\right) \sum_{i=1}^{N_{\theta}} \frac{\left(\frac{w}{U_{\infty}}\right)^{2} C_{t}}{N_{\theta}} \\
C_{P}=C_{Q} \lambda
\end{gathered}
$$

where; $C_{T}$ the thrust coefficient, $B$ is the number of blades, $R$ is the rotor radius, $w$ is the tangential velocity component, $U_{\infty}$ is the free stream velocity, $C_{t}$ is the tangential force coefficient, $C_{n}$ is the normal force coefficient, $D$ is the turbine diameter, $C_{Q}$ is the torque coefficient and $\lambda$ is the tip speed ratio.

\subsection{Numerical setup}

The model setup for the present study is produced based on the experimental and CFD analyses provided by Castelli et al. [16,17], Castelli and Benini [35] and Battisti et al. [36]. Details of geometrical and dynamic configurations of abovementioned studies and present study were listed in Tab. 1. The experimental and computational domains that have been reported by Castelli et al. (2010) [17] and Battisti et al. (2018) were illustrated in Fig. 4.

Table 1. Geometrical and dynamic details of the model and literature studies for experimental, computational and

\begin{tabular}{|c|c|c|c|c|c|c|}
\hline \multirow{2}{*}{ Features/type } & Sym. & $\begin{array}{l}\text { Battisti et al. } \\
\text { (2018) [36] }\end{array}$ & $\begin{array}{l}\text { Castelli et al. } \\
\text { (2010) [17] }\end{array}$ & $\begin{array}{l}\text { Castelli et al. } \\
\text { (2011) [16] }\end{array}$ & $\begin{array}{l}\text { Castelli and } \\
\text { Benini (2012) } \\
{[35]}\end{array}$ & Present study \\
\hline & & $\begin{array}{l}\text { Wind tunnel } \\
\text { experiment }\end{array}$ & $\begin{array}{l}\text { Wind tunnel } \\
\text { experiment }\end{array}$ & CFD analysis & CFD analysis & $\begin{array}{l}\text { Numerical } \\
\text { analysis }\end{array}$ \\
\hline Rotor diameter $(\mathrm{mm})$ & $D$ & 1028 & 1030 & 1030 & 1030 & 1028 \\
\hline Rotor height (mm) & $H$ & 1460 & 1456.4 & 1030 & 1030 & 1460 \\
\hline Airfoil type & - & NACA 0021 & NACA 0021 & NACA 0021 & NACA 0021 & NACA 0021 \\
\hline Number of blades & $N$ & 3 & 3 & 3 & 3 & 3 \\
\hline Chord length (mm) & $c$ & 85 & 85.8 & 85.8 & 85.8 & 85 \\
\hline Aerodynamic center & - & $0.5 \mathrm{c}$ & $0.5 \mathrm{c}$ & $0.5 \mathrm{c}$ & $0.5 \mathrm{c}$ & $0.5 \mathrm{c}$ \\
\hline Rotor solidity & $\sigma$ & 0.25 & 0.25 & N/A & N/A & 0.25 \\
\hline Frontal area $\left(\mathrm{m}^{2}\right)$ & $A$ & 1.5 & N/A & N/A & N/A & 1.5 \\
\hline Rotational velocity (rpm) & $\Omega$ & 400 & N/A & N/A & N/A & 400 \\
\hline Free stream velocity $(\mathrm{m} / \mathrm{s})$ & $U_{\infty}$ & $6-16$ & $9 \mathrm{~m} / \mathrm{s}$ & $9 \mathrm{~m} / \mathrm{s}$ & N/A & $6-16$ \\
\hline Tip speed ratio & $\lambda$ & $3.8-1.4$ & $0.6-1.2$ & $0.8-3.3$ & $2.6-4.1$ & $3.8-1.4$ \\
\hline
\end{tabular}
numerical validation

\section{Results and discussion}

Castelli et al. (2010) [17] studied on the numerical validation of a straight bladed Darrieus VAWT (Tab. 1) and they provided experimental results for a wind tunnel having 4000 x $3840 \mathrm{~mm}$ continuous test section which can be used for verification of numerical analyses (Fig. 4a). Experimental results were reported for free stream speed of $9 \mathrm{~m} / \mathrm{s}$ at various tip speed ratios considering no blockage correction. CFD analysis results were provided for the same geometrical details by Castelli et al. (2011) [16] using SST k- $\omega$ turbulence model at various y+ values for different wall functions. Again, Castelli and Benini [35] were provided CFD analyses at different tilting conditions. Model 0 of the abovementioned study which having zero tilt angle were used for validation of this study. 

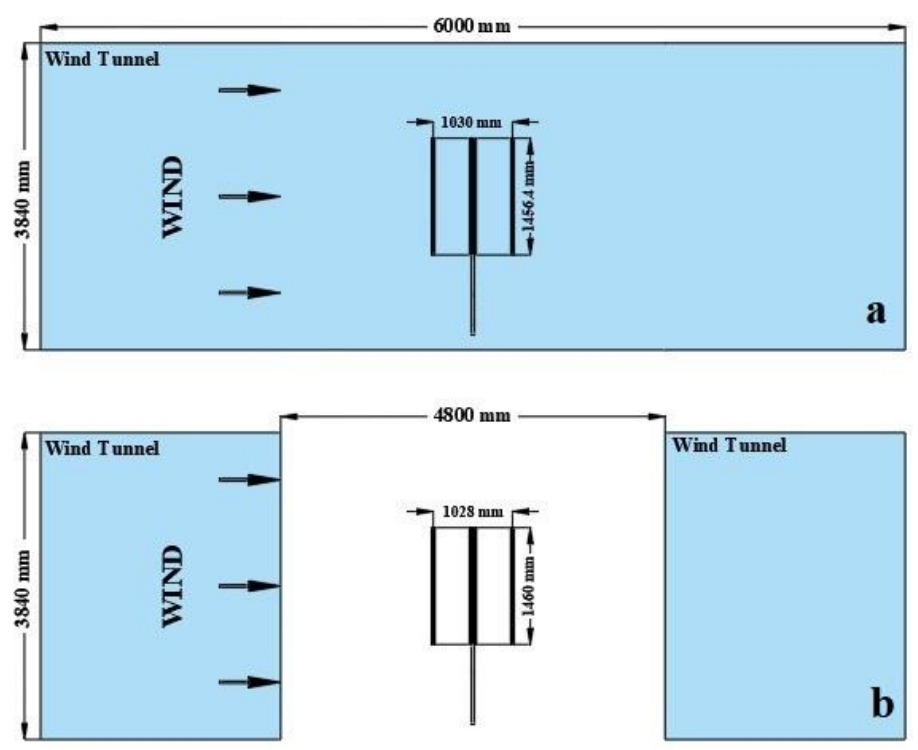

Figure 4. Illustration of experimental and computational setup reported by Castelli et al. (2010) [17] (a) and Battisti et al. (2018) [36] (b)

Consequently, Battisti et al. [36] reported wind tunnel experiment results of a straight bladed Darrieus turbine (Tab. 1) inside an open test section (free-jet configuration) at low turbulence intensity $(<1 \%)$ wind tunnel facility $(4000 \times 3840 \times 6000 \mathrm{~mm})$ in order to provide experimental benchmark data for researchers. Turbine's performance at steady $400 \mathrm{rpm}$ rotational speed for the freestream velocity varying between $6-16 \mathrm{~m} / \mathrm{s}$ were provided. The geometrical blockage ratio is defined as $1.5 \%$ by Battisti et al. [36]. However no blockage correction was reported for the experimental analysis. All experimental analyses are reported to be provided at Bovisa's low turbulence facility and Politecnico di Milano wind tunnel which is situated in Milan. $C_{P}$-TSR curves facilitate to compare the behavior of analyses that is provided using different methods eliminating also the geometrical considerations. The dynamic properties of the flow environment that is inputted to the QBlade software is summarized in Table 2. Comparison of power coefficient vs. tip speed ratio relationships of abovementioned literature studies and the present study has been provided in Fig. 5 .

It should be noted that, both experimental studies $[17,36]$ have similar behavior together with slight changes at the turbine geometry that is reported in Tab. 1 . The discrepancies are estimated to be sourced from the wind tunnel characteristics and sensitivity of the measurement equipment. The experimental analysis that is delivered by Battisti et al. [36] exhibits very low power coefficients at higher values of TSR (3-4), while the behavior of other computational and numeric analysis are consistent approximating to about 0.2-0.3. CFD analysis that is reported by Castelli et al. (2011) [16] shows relatively higher overall pressure coefficients (which is provided at $\mathrm{Re}=300 \times 10^{3}$ ) while the shape of $C_{P}$-TSR curve (bell shape) is very similar to the experiment that is conducted by [36]. It is predicted that, this behavior is a result of higher Re number which has also been discussed later.

In this study, various numerical analyses have been performed at different Re numbers. The green dotdash line represents the analysis at multiple Re number in which the blade sections have been assigned different Re numbers which is based on Battisti et al. [36]. Numerical results that are provided by QBlade for this curve is quite consistent at lower TSR $(<2.5)$. However, QBlade analyses for multiple Re numbers exhibit deteriorating performance at higher TSR ranges, for this study. Therefore, the performance of the rotor at $\mathrm{Re}=80000$ and $\mathrm{Re}=100000$ has also been included in Fig. 5 . It is observed that, more or less consistent results have been provided by QBlade software especially at 
low $R e$ number $(\operatorname{Re}=80000)$. Consequently, we reveal that, the suitable and accurate representation of Re number is significantly important while making numerical analysis with QBlade algorithm.

Table 2. Dynamic properties of QBlade analyses of present study

\begin{tabular}{ll|l|}
\hline Property & Parameter & QBlade view \\
\hline Free stream velocity & $6-16(\mathrm{~m} / \mathrm{s})$ & \\
Rotational speed & $400(\mathrm{rpm})$ & \\
TSR & $1.4-3.6$ & \\
Reynolds number & $80 \times 10^{3}-200 \times 10^{3}$ & \\
Viscosity & $1.5510^{-5}\left(\mathrm{~m}^{2} / \mathrm{s}\right)$ & \\
Air density & $1.155\left(\mathrm{~kg} / \mathrm{m}^{3}\right)$ & \\
\hline
\end{tabular}

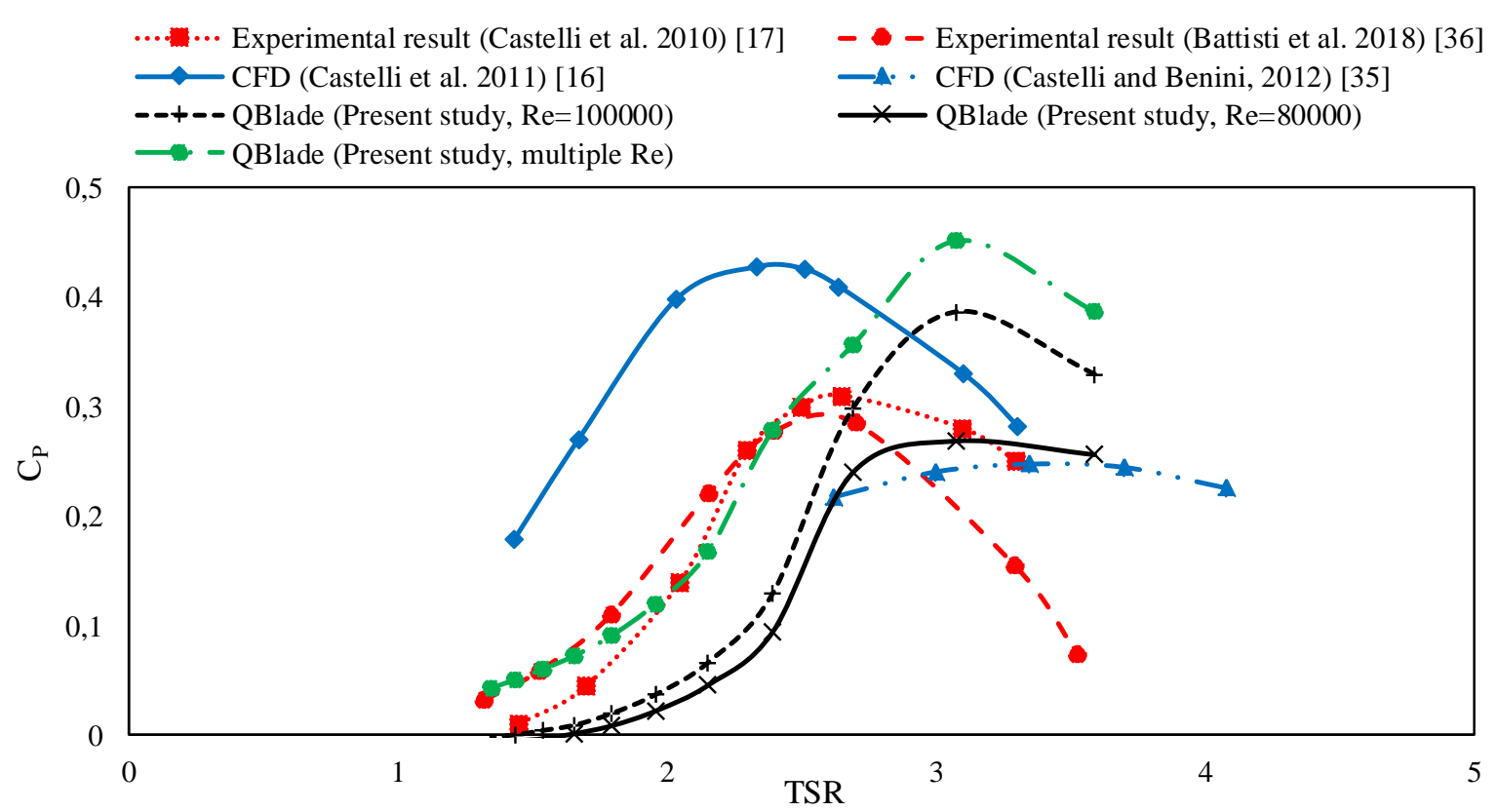

Figure 5. Efficiency comparison of experimental, computational and numerical (present study) results at different TSR

On the other hand, while experimental and computational studies have a bell-shaped $C_{P}$-TSR curve, QBlade analyses deliver rather straight or inclined linear behavior at right hand side of the curve. It has also been observed that, QBlade have overestimations in which the maximum $C_{P}$ value is shifted toward to the right side at higher TSR values relative to other experimental and computational studies.

The power output vs. free stream speed curves for experimental analysis [36] and present study have been provided in Fig. 6 for 400 rpm rotational velocity. The peak power for both analyses having similar geometric and dynamic configurations are approximating to each other where, the right and left side of the curves should be more discussed. Right hand of $P$ - $U_{\infty}$ curve $\left(U_{\infty}>10 \mathrm{~m} / \mathrm{s}\right)$ represents smaller TSR amounts $(<2.15)$ having very low power coefficient ranges for all analysis types (experimental, computational, numerical) which is less important than the region $U_{\infty}<10 \mathrm{~m} / \mathrm{s}$. It is obvious that, lower free stream speed ranges at LHS deliver high efficiency ranges of Darrieus turbines which should be noticed for higher power output. We realized that, $5<U_{\infty}<10$ velocity range is very important at 400 rpm rotational velocity in which TSR is between 2.15 and 4.3. In this region $C_{P}$-TSR curves which are discussed above can provide more accurate information for validation of QBlade analyses. 


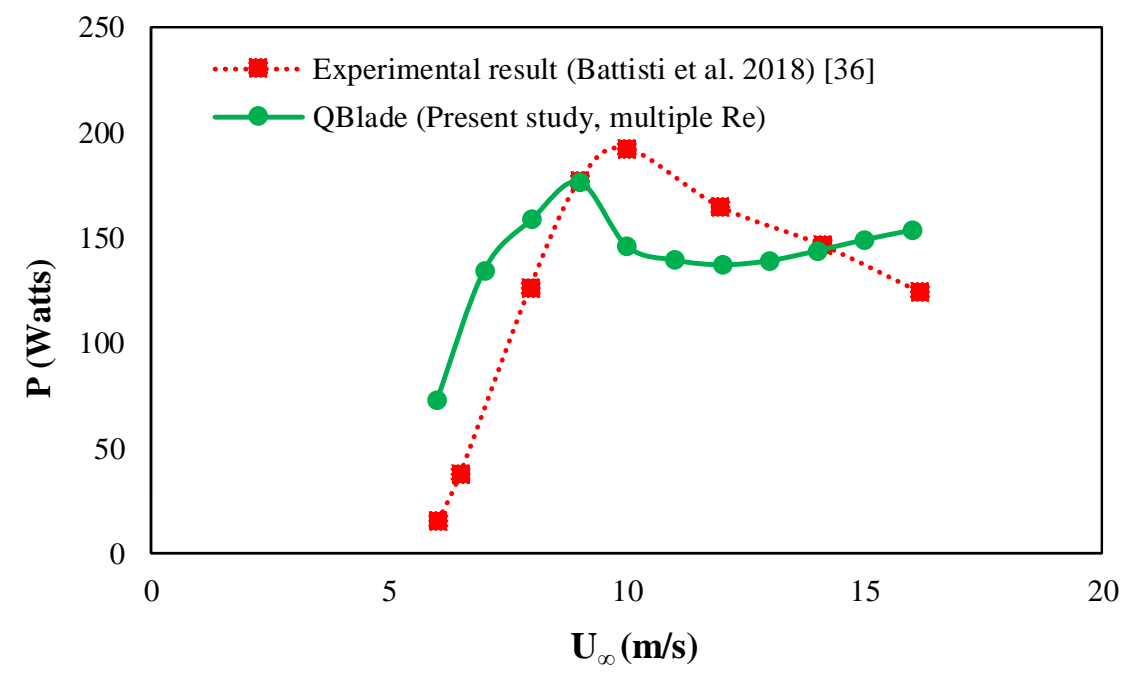

Figure 6. Output power vs. free stream speed comparison of experimental work [36] and this study

In order to assess the sensitivity of Reynolds number, Darrieus turbine performance results of QBlade algorithm for various Re numbers have been provided and summarized in Fig. 7. Again, it is observed that, higher Re numbers increases the overall power output and efficiency of Darrieus turbines by shifting the $P-U_{\infty}$ and $C_{P}$-TSR curves towards upward direction. Also, the maximum $C_{P}$ is observed at slightly higher TSR values.
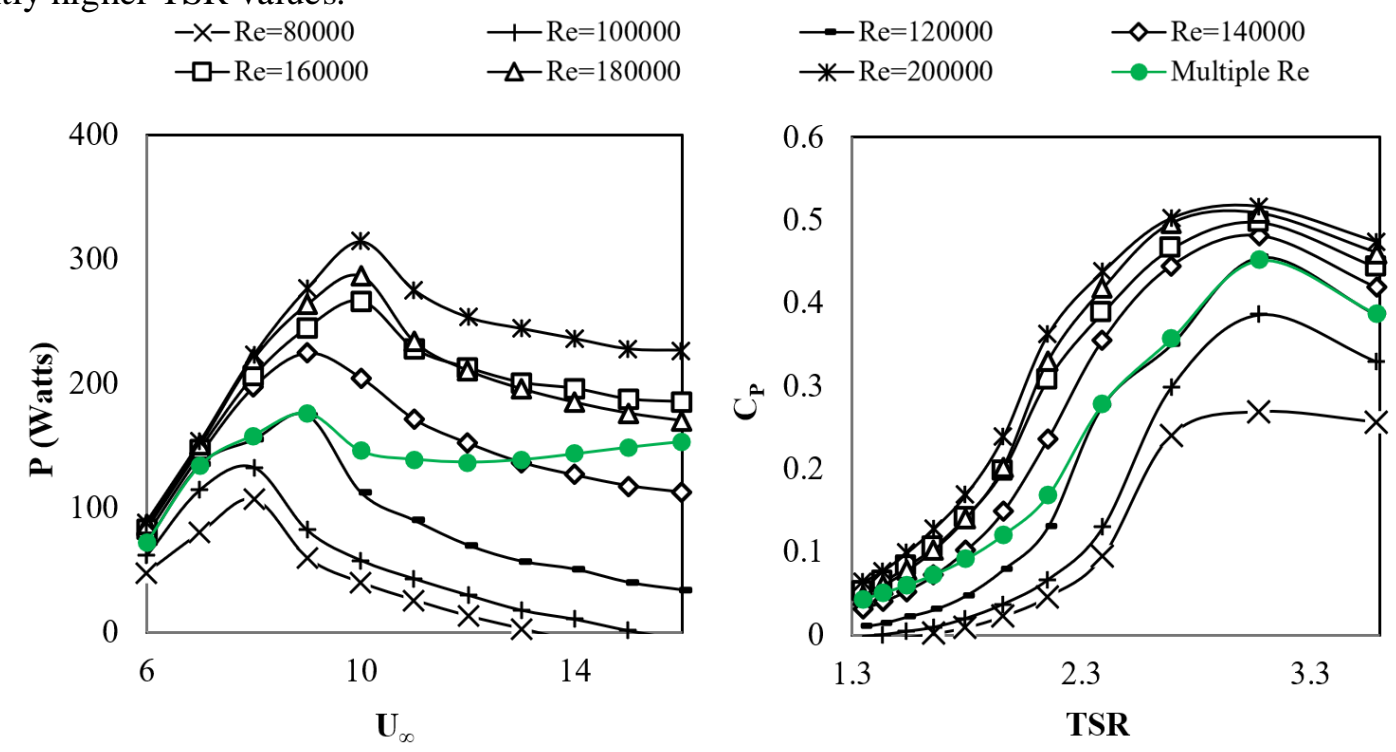

Figure 7. $P-U_{\infty}$ and $C P$ - TSR curves of QBlade analyses at various Re numbers

Generated torque is a function of blade length. Therefore, the geometry having the same rotor height is needed for comparison the algorithm's output with reference studies. None of the above studies explicitly mention from the torque values for $1460 \mathrm{~mm}$ rotor height, thus we could not provide a detailed comparison for torque values. Nevertheless, QBlade algorithm outputs for torque fluctuations of overall three blades at different azimuthal position have been illustrated in Fig. 8. It is observed that, at $9 \mathrm{~m} / \mathrm{s}$ steady wind speed, higher Re number shows explicitly higher torque outputs, as expected. Also, importance of the azimuthal position is clearly seen from the figure, in which, negative angles of attack deliver deteriorating performance. Thus, pitch regulation mechanism is suggested to maximize the power output from each blade by rotating the blades around their own axis to capture ideal angle of attack. 

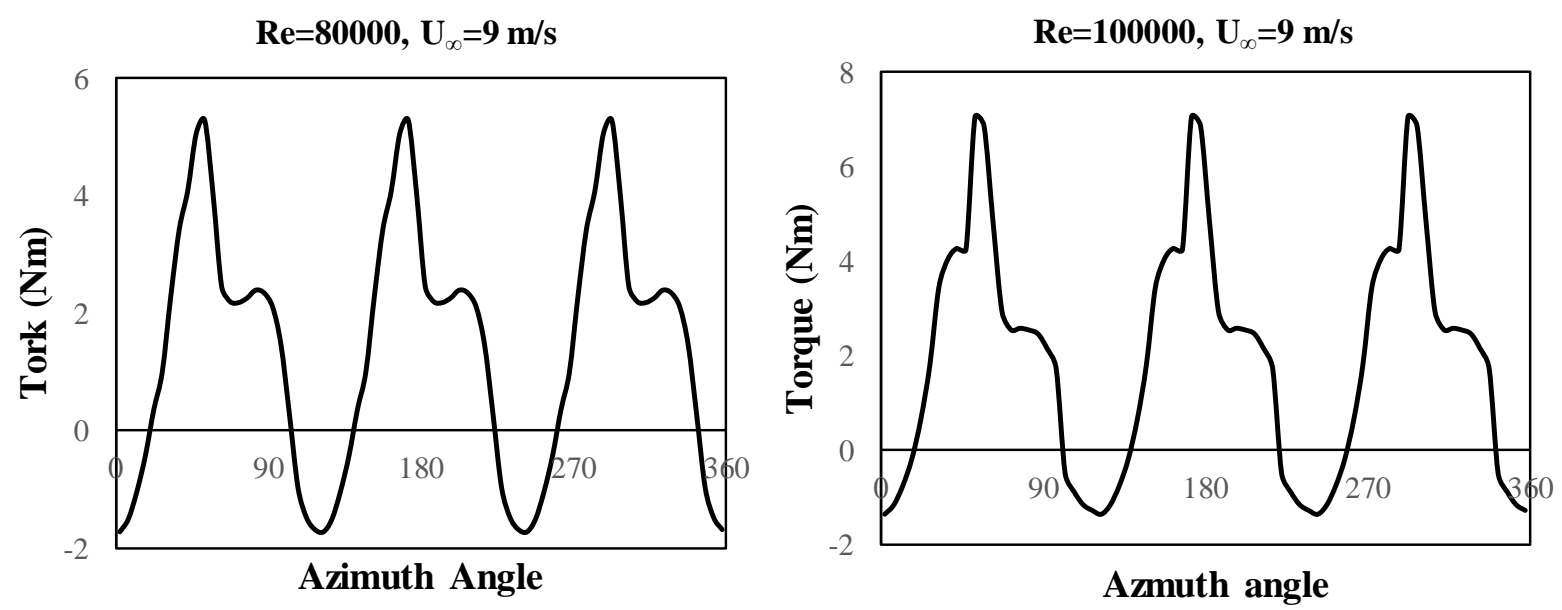

Figure 8. QBlade algorithm outputs for torque fluctuations of three bladed rotor

\section{Conclusion}

In this paper, the DMS theory which is exploited by QBlade algorithm in order of finding the performance of vertical axis wind turbines has been tested and verified comparing with the experimental and computational results of similar rotor geometry. The proposed turbine geometry has been numerically analyzed by the QBlade code at different free stream and rotational velocity conditions. Overall, the analysis results have been found to have a good agreement (Fig. 6), however special attention should be made at suitable specification of Re number. Because higher Re numbers increases the overall power output and efficiency of Darrieus turbines (Fig. 7). QBlade algorithm has a module facilitating to introduce Re number for each blade segment. On the other hand, the rotor geometry analyzed in this study at the specified free stream conditions exhibited relatively higher power coefficient at high TSR values after the maximum power coefficient (Fig. 5). Authors suggest that, special attention should be paid for the results generated at this region of $C_{P}$-TSR curve at relatively lower free stream speed values. Consequently, $P$ - $U_{\infty}$ curves are also found to be consistent together with non-significant discrepancies.

\section{References}

[1] Kalair, A.R., Abas, N., Ul Hasan, Q., Kalair, E., Kalair, A., Khan, N. (2019). Water, energy and food nexus of Indus Water Treaty: Water governance. Water-Energy Nexus. 2 (1), 10-24.

[2] Sims, R.E.H. (2004). Renewable energy: a response to climate change. Solar Energy. 76 (1-3), 9-17.

[3] Lian, J., Zhang, Y., Ma, C., Yang, Y., Chaima, E. (2019). A review on recent sizing methodologies of hybrid renewable energy systems. Energy Conversion and Management. 199 112027.

[4] Chaurasiya, P.K., Warudkar, V., Ahmed, S. (2019). Wind energy development and policy in India: A review. Energy Strategy Reviews. 24 342-357.

[5] Ghasemian, M., Ashrafi, Z.N., Sedaghat, A. (2017). A review on computational fluid dynamic simulation techniques for Darrieus vertical axis wind turbines. Energy Conversion and Management. 149 87-100.

[6] Aslam Bhutta, M.M., Hayat, N., Farooq, A.U., Ali, Z., Jamil, S.R., Hussain, Z. (2012). Vertical axis wind turbine - A review of various configurations and design techniques. Renewable and Sustainable Energy Reviews. 16 (4), 1926-1939. 
[7] Muratoglu, A., Yuce, M.I. (2017). Design of a River Hydrokinetic Turbine Using Optimization and CFD Simulations. Journal of Energy Engineering. 143 (4), 04017009.

[8] Kirke, B.K., Lazauskas, L. (2011). Limitations of fixed pitch Darrieus hydrokinetic turbines and the challenge of variable pitch. Renewable Energy. 36 (3), 893-897.

[9] Jagtap, M., Navale, L. (2017). Twist Angle Analysis of Helical Vertical Axis Wind Turbine (Vawt) Using Q-Blade. International Journal of Research Publications in Engineering and Technology. 3 (8), 2454-7875.

[10] Hosseini, A., Goudarzi, N. (2019). Design and CFD study of a hybrid vertical-axis wind turbine by employing a combined Bach-type and H-Darrieus rotor systems. Energy Conversion and Management. 189 49-59.

[11] Khan, M.J., Bhuyan, G., Iqbal, M.T., Quaicoe, J.E. (2009). Hydrokinetic energy conversion systems and assessment of horizontal and vertical axis turbines for river and tidal applications: A technology status review. Applied Energy. 86 (10), 1823-1835.

[12] Kim, S., Cheong, C. (2015). Development of low-noise drag-type vertical wind turbines. Renewable Energy. 79 199-208.

[13] Scungio, M., Arpino, F., Focanti, V., Profili, M., Rotondi, M. (2016). Wind tunnel testing of scaled models of a newly developed Darrieus-style vertical axis wind turbine with auxiliary straight blades. Energy Conversion and Management. 130 60-70.

[14] Bianchini, A., Balduzzi, F., Rainbird, J.M., Peiró, J., Graham, J.M.R., Ferrara, G., et al. (2015). On the influence of virtual camber effect on airfoil polars for use in simulations of Darrieus wind turbines. Energy Conversion and Management. 106 373-384.

[15] Eric, H. (2006). Windmills and Windwheels. In Wind Turbines, Springer Berlin Heidelberg, Berlin. 1-21.

[16] Raciti Castelli, M., Englaro, A., Benini, E. (2011). The Darrieus wind turbine: Proposal for a new performance prediction model based on CFD. Energy. 36 (8), 4919-4934.

[17] Raciti Castelli, M., Ardizzon, G., Battisti, L., Benini, E., Pavesi, G. (2010). Modeling Strategy and Numerical Validation for a Darrieus Vertical Axis Micro-Wind Turbine. 409-418.

[18] Ferreira, C.J.S., Bijl, H., Bussel, G. van, and Kuik, G. van (2007). Simulating Dynamic Stall in a 2D VAWT: Modeling strategy, verification and validation with Particle Image Velocimetry data. Journal of Physics: Conference Series. 75012023.

[19] D’Alessandro, V., Montelpare, S., Ricci, R., Secchiaroli, A. (2010). Unsteady Aerodynamics of a Savonius wind rotor: a new computational approach for the simulation of energy performance. Energy. 35 (8), 3349-3363.

[20] Khadir, L., Mrad, H. (2015). Numerical investigation of aerodynamic performance of darrieus wind turbine based on the magnus effect. 9 (4), 383-396.

[21] Ghazalla, R.A., Mohamed, M.H., Hafiz, A.A. (2019). Synergistic analysis of a Darrieus wind turbine using computational fluid dynamics. Energy. 116214.

[22] Wakui, T., Tanzawa, Y., Hashizume, T., Nagao, T. (2005). Hybrid configuration of darrieus and savonius rotors for stand-alone wind turbine-generator systems. Electrical Engineering in Japan (English Translation of Denki Gakkai Ronbunshi).

[23] Consul, C., Willden, R., Ferrer, E., McCulloch, M. (2009). Influence of Solidity on the Performance of a Cross-Flow Turbine. in: Proc. 8th Eur. Wave Tidal Energy Conf. , Uppsala, Sweden pp. 484-493.

[24] Brusca, S., Lanzafame, R., Messina, M. (2014). Design of a vertical-axis wind turbine: how the aspect ratio affects the turbine's performance. International Journal of Energy and Environmental Engineering. 5 (4), 333-340.

[25] Qblade (2018). Wind turbine design and simulation. Hermann Föttinger Institute of TU Berlin.

[26] Marten, D., Wendler, J., Pechlivanoglou, G., Nayeri, C.N., Paschereit, C.O. (2013). Qblade: An Open Source Tool for Design and Simulation of Horizontal and Vertical Axis Wind Turbines. International Journal of Emerging Technology and Advanced Engineering. 3 (3), 264-269. 
[27] Barooni, M., Ale Ali, N., Ashuri, T. (2018). An open-source comprehensive numerical model for dynamic response and loads analysis of floating offshore wind turbines. Energy. 154442 454.

[28] Bianchini, A., Marten, D., Tonini, A., Balduzzi, F., Nayeri, C.N., Ferrara, G., et al. (2018). Implementation of the "Virtual Camber" Transformation into the Open Source Software QBlade: Validation and Assessment. Energy Procedia. 148 210-217.

[29] Mahmuddin, F. (2017). Rotor Blade Performance Analysis with Blade Element Momentum Theory. Energy Procedia. 105 1123-1129.

[30] Suresh, A. and Rajakumar, S. (2019). Design of small horizontal axis wind turbine for low wind speed rural applications. Materials Today: Proceedings.

[31] Rahimian, M., Walker, J., Penesis, I. (2018). Performance of a horizontal axis marine current turbine- A comprehensive evaluation using experimental, numerical, and theoretical approaches. Energy. 148 965-976.

[32] Akour, S.N., Al-Heymari, M., Ahmed, T., Khalil, K.A. (2018). Experimental and theoretical investigation of micro wind turbine for low wind speed regions. Renewable Energy. 116 215223.

[33] Bangga, G., Dessoky, A., Lutz, T., Krämer, E. (2019). Improved double-multiple-streamtube approach for H-Darrieus vertical axis wind turbine computations. Energy. 182 673-688.

[34] Liu, J., Lin, H., Zhang, J. (2019). Review on the technical perspectives and commercial viability of vertical axis wind turbines. Ocean Engineering. 182 608-626.

[35] Castelli, M.R. Benini, E. (2011). Effect of Blade Inclination Angle on a Darrieus Wind Turbine. Journal of Turbomachinery. 134 (3).

[36] Battisti, L., Persico, G., Dossena, V., Paradiso, B., Raciti Castelli, M., Brighenti, A., et al. (2018). Experimental benchmark data for H-shaped and troposkien VAWT architectures. Renewable Energy. 125 425-444.

[37] Muratoglu, A. (2014). Design and simulation of a riverine hydrokinetic turbine, Ph.D. thesis, University of Gaziantep, 2014.

[38] Morgado, J., Vizinho, R., Silvestre, M.A.R., and Páscoa, J.C. (2016). XFOIL vs CFD performance predictions for high lift low Reynolds number airfoils. Aerospace Science and Technology. 52 207-214.

[39] Zhang, S., Li, H., Abbasi, A.A. (2019). Design methodology using characteristic parameters control for low Reynolds number airfoils. Aerospace Science and Technology. 86 143-152.

[40] Yirtici, O., Cengiz, K., Ozgen, S., Tuncer, I.H. (2019). Aerodynamic validation studies on the performance analysis of iced wind turbine blades. Computers \& Fluids. 192104271.

[41] Glauert, H. (1963). Airplane Propellers. vol. Aerodynamic Theory Volume IV. WF Durand.

[42] Templin, R.J. (1974). Aerodynamic performance theory for the NRC vertical-axis wind turbine. NASA STI/Recon Technical Report N. 76.

[43] Strickland, J.H. (1975). The Darrieus Turbine: A Performance Prediction Method Using Multiple Stream Tubes. in: Sand75-0431, p. 94550.

[44] Saber, E., Afify, R., Elgamal, H. (2018). Performance of SB-VAWT using a modified double multiple streamtube model. Alexandria Engineering Journal. 57 (4), 3099-3110.

[45] Paraschivoiu, I., Delclaux, F. (1983). Double multiple streamtube model with recent improvements (for predicting aerodynamic loads and performance of Darrieus vertical axis wind turbines). Journal of Energy. 7 (3), 250-255.

[46] Biadgo, A.M., Simonović, A., Komarov, D., Stupar, S. (2013). Numerical and analytical investigation of vertical axis wind turbine. FME Transactions. 41 (1), 49-58.

[47] Paraschivoiu, I. (2002). Wind turbine design: with emphasis on Darrieus concept. Polytechnic International Press, Canada. 
[48] Paraschivoiu, I (1982). Aerodynamic loads and performance of the Darrieus rotor. Journal of Energy. 6 (6), 406-41 